призведе до створення нових робочих місць та збільшення роботи транспортної інфраструктури; дасть змогу набути Україні нової якості - ініціатора форматів, а не споживача запропонованих проектів. Але на шляху до ефективної гармонізації інтеграційних процесів стоїть необхідність відповідності національної транспортної системи високим стандартам та технічним вимогам ринку Свросоюзу.

\section{СПИСОК ЛІТЕРАТУРИ}

1. Бараш Ю. С. Управління залізничним транспортом країни: Монографія / Ю. С. Бараш. - Д.: Вид-во Дніпропетр. нац. ун-ту залізн. трансп. ім. акад. В.Лазаряна, 2006. - 252 с.
2. Дикань В. Л. Забезпечення ефективності інноваційної діяльності підприємств залізничного транспорту: Монографія / В. Л. Дикань, В. О. Зубенко. - Х.: УкрДАЗТ, 2008. - 194 с.

3. Ейтутис Г. Д. Теоретикопрактичні основи реформування залізниць України: Монографія / Г.Д.Ейтутис. Ніжин: ТОВ «Видавництво «АспектПоліграф», 2009. - 240 с.

4. Sładkowski, A. \& Pamuła, W. (eds.) Intelligent Transportation Systems Problems and Perspectives. Studies in Systems, Decision and Control 32. Cham, Heidelberg, New York, Dordrecht, London: Springer. 2015. 316 p. ISBN 978-3-31919149-2.

Стаття надійшла: 21.06.16p.

УДК 656.072

\title{
ПІДХІД ЩОДО ФОРМУВАННЯ ТРАНСПОРТНОЇ МОДЕЛІ СИСТЕМИ ПАСАЖИРСЬКОГО ТРАНСПОРТУ В МАЛИХ МІСТАХ
}

\author{
Любий С.В., к.т.н., доцент (ХНАДУ)
}

В статті запропоновано підхід щуодо визначення доцільності об'єднання зупинних пунктів маршрутів пасажирського транспорту до транспортного району на основі прийнятого способу формування моделі попиту на перевезення населення малих міст. В якості показника відповідності моделі реальним умовам слід використовувати частку значущих кореспондениій у задачі лінійного програмування при формуванні граничних станів матрищь кореспонденцій кожного міського маршруту.

Ключові слова: транспортне планування, малі міста, транспортні райони, маршрутні кореспонденції.

\section{ПОДХОД К ФОРМИРОВАНИЮ ТРАНСПОРТНОЙ МОДЕЛИ СИСТЕМЫ ПАССАЖИРСКОГО ТРАНСПОРТА В МАЛЫХ ГОРОДАХ}

\author{
Любый Е.В., к.м.н., доцент (ХНАДУ)
}

В статье предложен подход к определению иелесообразности объединения остановочных пунктов маршрутов пассажирского транспорта в транспортный 
район на основе принятого способа формирования модели спроса на перевозку населения малых городов. В качестве показателя соответствия модели реальным условиям можно использовать долю значимых корреспонденций в задаче линейного программирования при формировании граничных состояний матрии корреспонденций каждого городского маршрута.

Ключевые слова: транспортное планирование, малые города, транспортные районы, марирутные корреспонденции.

\section{AN APPROACH OF THE FORMATION MODEL OF THE TRANSPORT OF MASS TRANSIT IN SMALL TOWNS}

\section{Liubyi E.V., Candidate of Technical Sciences, Associate Professor (KhNAHU)}

This paper proposes an approach to determining the feasibility of combining the stopping point of the route of passenger transport in the transport area on the basis of the adopted method of forming the pattern of demand for public transport of small towns. An indicator of model fit the actual conditions, you can use a share of significant correspondences in a linear programming problem in the formation of the boundary conditions of a matrix of correspondence each urban route. The results can be used to address the issues of transport planning and modeling route passenger transport systems in small and medium-sized towns.

Keywords: transport planning, small towns, transportation areas, shuttle correspondence.

\begin{abstract}
Постановка проблеми та ї̈ зв'язки 3 науковими та практичними завданнями. Однією з головних проблем при формуванні маршрутних мереж міст $\epsilon$ моделювання транспортних районів (ТР). Виходячи 3 того, що кінцевою метою моделювання маршрутних мереж $\epsilon$ отримання максимальних i достовірних результатів вибору оптимального стану системи дослідження, необхідним $\epsilon$ врахування наступних вимог [1]: коректність подавання реальних об'єктів вершиною графа транспортної мережі; можливість отримання об'єктивної інформації про ТР; стабільність характеристик ТР при зміні структури об'єктів.
\end{abstract}

Аналіз останніх досліджень $i$ публікацій та виділення невирішених частин загальної проблеми. Існуючі вимоги до моделювання транспортних мереж дуже суперечливі, про що свідчать наведені в [2] приклади. Звідси випливає, що кількість ТP залежатиме від $\begin{array}{lcc}\text { поставленої } & \text { мети моделювання } & \text { та } \\ \text { можливостей } & \text { інструментів, } & \text { iз }\end{array}$ використанням яких воно проводиться.

Для формування правильних висновків із моделювання ТР обов'язковим $\epsilon$ врахування наступних особливостей малих міст:

1. Населення малих міст здебільшого тяжіє до пересувань пішки (рис. 1) [3]. У сучасних умовах виділяють два основні показника, які впливають на середній по місту коефіцієнт користування транспортом $\varphi_{\text {mp.cp: }}$ населеність міста $H$ i рівень його автомобілізації. Як стає очевидним, що

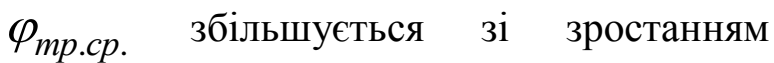
населеності міста $H$ і рівня автомобілізації (крива 1 відповідає невисокому рівню автомобілізації - 50 авт./1000 жит., крива 2 - помірному рівню - 50 - 150 авт./1000 жит., крива 3 високому рівню - до 500 авт./1000 жит.). 


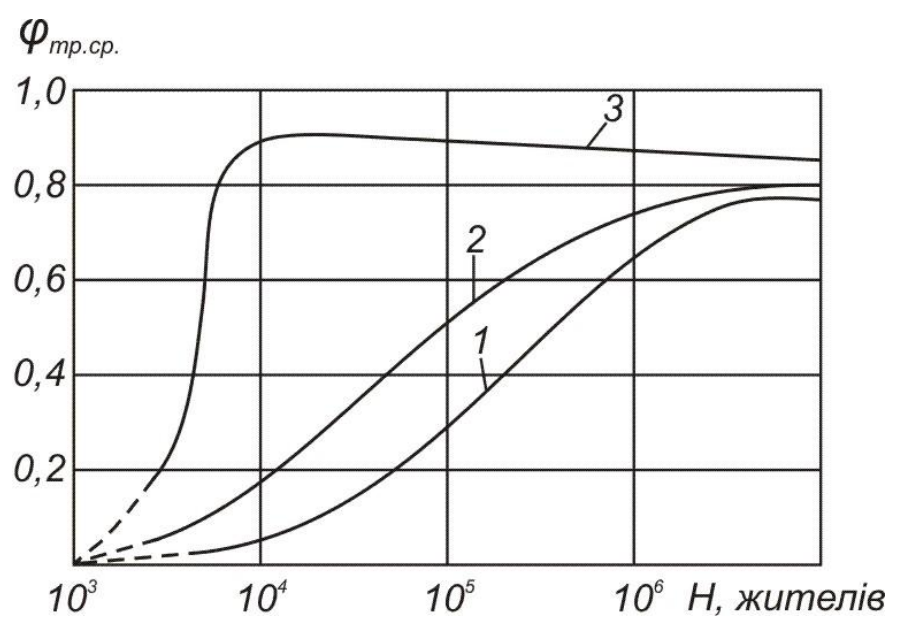

Рис. 1. Залежність середнього по місту коефіиієнта користування транспортом від його населеності та рівня автомобілізації

2. Площа малих міст $є$ незначною і розподіл їхньої території за зупинними пунктами (ЗП) призводитиме до повної "умовності" цих ТР і нестабільності їхніх характеристик.

3. Невисока щільність маршрутних систем малих міст призводить до появи значних за протяжністю ізольованих ділянок маршрутів. Об'єднання ЗП до ТР на таких ділянках не буде супроводжуватися втратою точності порівняльної оцінки ефективності варіантів маршрутної системи.

Необхідно відзначити, що сучасні програмні пакети, які використовується для транспортного планування міст, дають можливість створення ТР навколо кожного ЗП [4]. Але така повна деталізація для транспортних систем малих міст $\epsilon$ недоцільною виходячи 3 відносно малих масштабів об'єкта. Тому перед початком моделювання транспортної мережі необхідно провести дослідження для з'ясування необхідності об'єднання кількох ЗП до ТР.

$$
\text { Ураховуючи те, що }
$$

запропонований в [5] спосіб формування моделі попиту на маршрутні пересування пасажирів малих міст дає різноманітні результати при різному ступеню деталізації моделі, що обумовлено особливостями задачі лінійного програмування (ЗЛП). Доцільність об'єднання ЗП до ТР можна довести, використовуючи такий показник, як частка значущих кореспонденцій, що визначається на основі значень складових приведеної в [5] системи рівнянь. Для визначення складових цієї системи рівнянь необхідно знати іiі кількісні характеристики, а саме: можливу кількість кореспонденцій між ЗП на маршруті, кількість рівнянь у системі та вільних змінних.

Метою cmammi $\epsilon$ розробка підходу моделювання ТР, що враховує сучасні принципи формування моделей транспортних мереж та особливості транспортного обслуговування населення малих міст.

Виклад основного матеріалу дослідження. На сьогодні для визначення загальної кількості кореспонденцій між ЗП маршруту використовують залежність $[6,7]$

$$
h=\frac{n \cdot(n-1)}{2},
$$

де $n$ - кількість ЗП на маршруті, од.

На жаль, авторами [6, 7] наданий лише кінцевий вигляд рівняння (1), тому для з'ясування сутності проведемо його виведення. Для цього використовуємо 
основні положення комбінаторики [8]. Необхідно розуміти, що в даному випадку нас не цікавить послідовність елементів (кореспонденцій) у комбінації, а цікавить iii склад, тобто кількість. Для вирішення цього завдання в комбінаториці використовують поєднання. Для розуміння сутності питання наведемо визначення поняття "поєднання": $k$ поєднаннями $3 n$ елементів називають всі можливі

$k$-розміщення, які складено 3 цих елементів і що відрізняються один від одного складом, але не послідовністю елементів. Кількість $k$-поєднань, які можна скласти $3 n$ елементів, визначають за наступною залежністю [8]:

$$
C_{n}^{k}=\frac{n !}{k ! \cdot(n-k) !}
$$

Для нашого випадку $n$ дорівнює кількості ЗП на маршруті, а як $k$ використовується мінімальна кількість ЗП, яка створює кореспонденцію, тобто $k=2=$ const. Звідси випливає, що (2) можна записати наступним чином:

$$
C_{n}=\frac{n !}{2 !(n-2) !}
$$

Враховуючи

факторіала [8], вираз (3) можна представити як

$$
C_{n}=\frac{1 \cdot 2 \cdot \ldots \cdot(n-3) \cdot(n-2) \cdot(n-1) \cdot n}{2 \cdot[1 \cdot 2 \cdot \ldots \cdot(n-3) \cdot(n-2)]}
$$

Після проведення скорочення отримаємо кінцевий вигляд рівняння для визначення можливої кореспонденцій

$$
C_{n}=h=\frac{n \cdot(n-1)}{2} .
$$

залежності між кореспонденціями та місткостями ЗП 3 відправлення та прибуття пасажирів [5], можна стверджувати, що одним рівнянням у системі можна знехтувати, тобто вираз (7) матиме наступний вигляд:

$$
y=2 \cdot(n-1)-1 .
$$

Але, враховуючи особливості маршрутних матриць кореспонденцій [5], рівняння (5) набуває в

А 3 урахуванням особливостей

$$
h=\frac{n \cdot(n-1)}{2}-2 .
$$

Наступною характеристикою системи рівнянь є кількість рівнянь у системі або, іншими словами, кількість значущих кореспонденцій. Як і у випадку із можливою кількістю кореспонденцій на маршруті, даний показник визначається виходячи із кількості ЗП маршруту. У [7] пропонується визначати кількість рівнянь системи за залежністю

$$
y=2 \cdot(n-1) .
$$

Виходячи із доведеної лінійної маршрутних матриць кореспонденцій [5], рівняння (8) набуває вигляду

$$
y=2 \cdot(n-1)-3 .
$$

Для визначення кількості вільних змінних у системі рівнянь необхідно знати попередні дві характеристики системи

$$
k_{o}=k-y \text {. }
$$

Розроблені залежності розрахунку складових системи [5] дають можливість встановити застку значущих кореспонденцій, яка визначатиметься наступним чином: 


$$
\Delta_{3 н}=y / k
$$

Використовуючи вирази (6) і (9), частку значущих кореспонденцій можна представити як

$$
\Delta_{3 H}=\frac{4 \cdot n-10}{n \cdot(n-1)-4} .
$$

Необхідно зазначити, що в більшості випадків при проведенні натурних спостережень мінімальним часовим інтервалом, за який отримуються вихідні дані, $є$ час рейсу ТЗ на маршруті. Звідси випливає, що в кожного рейсу буде своя матриця кореспонденцій i обстежуватися повинні всі рейси, а це, в свою чергу, свідчить про те, що $\Delta_{3 н} \epsilon$ випадковою величиною. У загальному випадку $\Delta_{\text {зн }}$ буде залежати від варіанту об'єднання ЗП у ТР. При цьому необхідно установити наступні обмеження: в один ТР повинні об'єднуватися ЗП, які $\epsilon$ суміжними на трасі маршрутів; включення в ТР додаткового ЗП не повинно призводити до збільшення кількості маршрутів, які проходять через ТР.

Слід зазначити, що обсяг спостережень, які необхідні для суцільного обстеження всіх рейсів за період розглядання, завеликий для його реалізації в рамках даного дослідження. Тому необхідно проводити вибіркове обстеження роботи транспортних засобів на маршрутах і в його результатах будуть зустрічатися ЗП, для яких виконуватиметься умова балансування $D=A$. Насправді такі ЗП не будуть існувати якийсь тривалий час. Таким чином, це свідчить про те, що достовірність значень $D_{i}, A_{j}, h_{i j}$ для 3П, а не ТР, не може бути оцінена вибірковим обстеженням. Тому оцінити доцільність об'єднання ЗП до ТР можна тільки на основі $\Delta_{3 н}$. А випадковий характер появи нульових місткостей ЗП у результаті обстеження дає можливість використовувати цей факт для оцінки фактичних значень $\Delta_{\text {зн }}$.

Висновок про доцільність об'єднання ЗП до ТР робиться на основі результатів обстеження кореспонденцій для матриць кореспонденцій кожного напрямку маршруту шляхом визначення показників табл. 1.

Дані про кількість маршрутів та ЗП на кожному маршруті отримуються на етапі збору вихідної інформації про маршрутну мережу міста. Інформація для заповнення третього та четвертого стовпчиків таблиці $є$ результатом обробки карток для проведення обстеження кореспонденцій в малих містах. До третього стовпчика табл. 1 заноситься інформація про загальну кількість значущих кореспонденцій, тобто таких кореспонденцій, які не дорівнюють нулю.

Далі необхідно визначити кількість ЗП, які відповідають умові $D_{i} \cup A_{j}>0$. У свою чергу, загальна кількість кореспонденцій визначається на основі кількості значущих ЗП (п'ятий стовпчик табл. 1). Частка значущих кореспонденцій визначається як відношення кількості значущих кореспонденцій (третій стовпчик табл. 1) до загальної кількості кореспонденцій (п'ятий стовпчик табл. 1). Необхідна кількість ТР приймається виходячи 3 найближчих значень частки значущих кореспонденцій. Висновок про доцільність об'єднання ЗП до ТР робиться виходячи 3 наступної умови: якщо необхідна кількість ТР менша, ніж кількість значущих ЗП, отриманих за результатами обстежень, то об'єднувати ЗП до ТР необхідно. В іншому випадку в об'єднанні немає потреби. 
Результати визначення дочільності об'єднання ЗП до ТР (за напрямками)

\begin{tabular}{|c|c|c|c|c|c|c|}
\hline 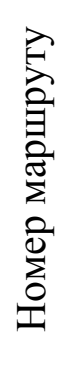 & 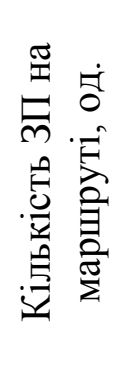 & 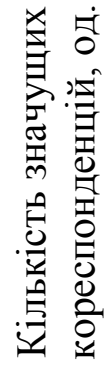 & 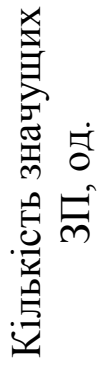 & 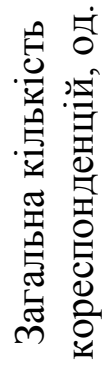 & 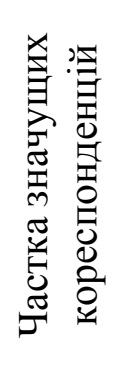 & 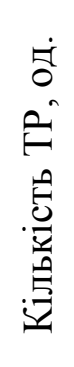 \\
\hline 1 & 2 & 3 & 4 & 5 & 6 & 7 \\
\hline$\ldots .$. & $\ldots \ldots$ & $\ldots \ldots$ & $\ldots \ldots$ & $\ldots \ldots$ & $\ldots \ldots$ & $\cdots$ \\
\hline
\end{tabular}

\section{Висновки даного досліджсеня $\boldsymbol{i}$} перспективи подальших робіт у цьому напрямку. Однією 3 головних проблем при формуванні транспортних моделей міст $\epsilon$ моделювання ТР. Для подолання цієї проблеми необхідно розробити методику моделювання ТР, яка б ураховувала сучасні принципи формування моделей транспортних мереж та особливості малих міст. При формуванні транспортних моделей малих міст необхідно визначити доцільність об'єднання ЗП до ТР на основі прийнятого способу формування моделі попиту на перевезення. У цьому випадку показником відповідності моделі реальним умовам може бути частка значущих кореспонденцій у ЗЛП при формуванні граничних станів матриць кореспонденцій кожного міського маршруту.

\section{СПИСОК ЛІТЕРАТУРИ}

1. Горбачев П. Ф. Основы теории транспортных систем: учеб. пособ. / П. Ф. Горбачев, И. А. Дмитриев. - Харьков : Изд-во ХНАДУ, 2002. - 202 с.

2. Луб'яний П. В. Ефективність пасажирської маршрутної мережі міст : автореф. дис. на здобуття наук. ступеня канд. техн. наук: 05.22.01 "Транспортні системи" / П. В. Луб'яний. - Харків : ХНАДУ, 2005. - 20 с.
3. Ефремов И. С. Теория городских пассажирских перевозок: учеб. пособ. для вузов / И. С. Ефремов, В. М. Кобозев, В. А. Юдин. - М.: Высшая школа. - 1980. $535 \mathrm{c}$.

4. Швецов В. Л. Управление транспортной системой на основе компьютерной модели PTV VISION ${ }^{\circledR}$ VISUM / В. Л. Швецов, Е. А. Андреева // Сборник докладов 7-й междунар. конф. "Организация и безопасность дорожного движения в крупных городах". - СПб: СПб гос. Архитектурно - строительный университет. - 2006. - С. $190-192$.

5. Любий С. В. Визначення попиту на пересування населення малих міст маршрутним пасажирським транспортом : автореф. дис. на здобуття наук. ступеня канд. техн. наук: 05.22.01 "Транспортні системи" / Є. В. Любий. - Харків : ХНАДУ, 2012. - 22 с.

6. Автоматизация управления транспортными системами / под. ред. А. А. Воронова. - М. : Наука, 1984. - 272 с.

7. Спирин И. В. Городские автобусные перевозки: справочник / И. В. Спирин. - М.: Транспорт, 1991. - 238 c.

8. Виленкин Н. Я. Комбинаторика / Н. Я. Виленкин. - М., Изд. "Наука", 1969. $-328 \mathrm{c}$.

Стаття надійшла: 6.06.16p. 